\title{
Bendito Baudelaire
}

\author{
Álvaro Faleiros
}

Resumo: A recepção de Baudelaire no Brasil passou, nos anos 1930, por um período de consagração acadêmica, nas palavras de Antonio Candido. Nosso intuito aqui é refletir sobre o modo como Baudelaire se tornou, ao longo do século xx, no Brasil, um poeta acadêmico e convencional, e em que medida essa apropriação de Baudelaire lança luz sobre a poesia brasileira de meados do século passado.

Palavras-chave: Baudelaire, recepção, tradução, literatura brasileira.

Résumé: La réception de Baudelaire au Brésil dans les années 1930 est, selon Antonio Candido, une époque de consécration académique. Nous aimerions discuter par quels moyens tout au long du vingtième siècle Baudelaire est devenu, au Brésil, un poète académique et conventionnel e dans quelle mesure cette appropriation de Baudelaire apporte de la lumière sur la poésie brésilienne de la moitié du siècle dernier.

Mots-clés: Baudelaire, réception, traduction, littérature brésilienne.

Abstract: The welcoming of Baudelaire in Brazil has passed, in the 1930s, through a period of academic consecration, in the words of Antonio Candido. Our purpose here is to reflect on the way how Baudelaire became, along the zoth century, in Brazil, an academic and conventional poet, and in what measure that appropriation of Baudelaire illuminates Brazilian poetry in the mid-2oth century.

Keywords: Baudelaire, welcoming, translation, Brazilian literature. 
Como apontou Antonio Candido em seu estudo sobre "os primeiros baudelairianos", depois da década de 1930, houve, em relação a Baudelaire, "uma espécie de consagração acadêmica, expressa em muitas traduções quase todas devidas a poetas convencionais". É o próprio Antonio Candido que chama a atenção para o fato de que esse momento de consagração acadêmica "se apoiou na Academia Brasileira de Letras e no Jornal do Comércio, e [que] um dos resultados foram cinco pequenos volumes e alguns artigos esparsos de Félix Pacheco"; 2 ele ainda acrescenta que essa "verdadeira campanha" promovida por Félix Pacheco talvez "haja contribuído para estimular certos trabalhos (mais sólidos), como as traduções de Guilherme de Almeida".

Apesar de não parecerem sólidos aos olhos de Candido, os trabalhos de Pacheco são um importante momento da recepção de Baudelaire no Brasil, que nos dá algumas pistas para compreender o modo como o maldito poeta francês se tornou, em nossas plagas, tão convencional.

Já nas primeiras páginas de seu discurso intitulado Do sentido do azar e do conceito da fatalidade em Baudelaire, publicado em 1933 pelas Oficinas Tipográficas do Jornal do Comércio, Félix Pacheco afirma que, em Baudelaire:

As suas revoltas, a independência leonina do seu modo de gravar no verso o sentimento da belleza, a sua compreensão multiforme do pecado, só comparável à vehemencia dos seus desejos de immediato arrependimento, tudo nelle era um cascatear nunca visto de symbolos, soando em rythmos, que, até então, ainda ninguem exibira... ${ }^{4}$

Como se pode notar, para Pacheco, a presença do pecado é acompanhada de "imediato arrependimento", não havendo, pois, a possibilidade de Baudelaire visar à exposição e à explicitação do próprio Mal. Estamos aqui distantes da leitura de Auerbach, para quem as As flores do mal:

1. Mello e souzA, Antonio Candido de. "Os primeiros baudelairianos". In: A educação pela noite e outros ensaios. São Paulo: Ática, 1989, p. 27.

2. Ibid.

3. Ibid.

4. PACHeco, Félix. Do sentido do azar e do conceito da fatalidade em Baudelaire. Rio de Janeiro: Oficinas Tipográficas do Jornal do Comércio, 1933, p. 16. 
É um livro de desesperança sombria, de tentativas absurdas e fúteis de inebriar e escapar. [...] Os que são tomados pelo horror não falam do frisson nouveau, não gritam bravo nem congratulam o poeta por sua originalidade. Até mesmo a admiração de Flaubert, apesar de lapidarmente formulada, é estética demais. Muitos críticos posteriores deram por evidente que o livro só poderia ser considerado de um ponto de vista estético e rejeitaram com escárnio outra possibilidade de abordagem. ${ }^{5}$

A leitura estética a que se refere Auerbach coincide, de fato, com a proposta de Pacheco. Imbuído do espírito de resgatar Baudelaire, Pacheco, na página seguinte do referido discurso, acrescenta que as negações satanistas de Baudelaire "nunca foram signal de irreligiosidade visceral, mas simples echos passageiros da grande tragédia do espírito, em lucta contra o irremovível dos maus fados e contra as fascinações da carne e do demonio". ${ }^{6}$

A resposta de Pacheco aos poetas que optaram por destacar o satanismo presente em Baudelaire visa a trazer à tona sua suposta religiosidade e, sobretudo, destacar o que chama de "valor educativo do seu poder de imaginação,? pois, para Pacheco, o traço principal de Baudelaire é:

o de nos consolar, ao embalo da formosura, entre os sonhos, que são formas nobres de ascensão, e os desejos, que nem sempre significam impulsos ingenitos para o mal, antes traduzem, não raro, uma forma litteraria superior de contrabater com efficacia o vicio. ${ }^{8}$

A força de Baudelaire se encontraria, assim, na existência de "uma forma literária superior" que, mais adiante no ensaio, Pacheco associa, por meio da aproximação entre Baudelaire e Valéry, a uma "educação matemática". ${ }^{9}$ Nessa passagem, Félix Pacheco anuncia princípios de algumas das poéticas brasileiras em gestação à época, a saber, a poética da geração de 45 e a dos poetas concretos. Como aponta Cacaso, em

5. AUERBACH, Erich. "As Flores do mal e o sublime". In: Ensaios de literatura ocidental. Tradução de Samuel Titan Jr. e José M. M. de Marcelo. São Paulo: Editora 34/Duas Cidades, 2007, pp. 331-332.

6. PACHeco, Félix. Do sentido do azar e do conceito da fatalidade em Baudelaire, op. cit., p. 17.

7. Ibid.

8. Id., p. 23.

9. Id., p. 33 . 
seu ensaio "Atualidade de Mário de Andrade": ao contrário da poética de inovação participante do modernismo, a poética de 45 vai cultivar uma concepção exterior da forma [...]. O academismo é reconduzido à cena contemporânea [... e] o que ressalta é o seu passadismo". ${ }^{10}$

Nesse contexto, invocar e traduzir Baudelaire servem para lançar luz sobre os aspectos formais e o aspecto supostamente pedagógico nele implicados e, desse modo, educar os sentidos por meio de um "rigor de técnica", para retomar outro termo utilizado por Pacheco. ${ }^{11} \mathrm{~A}$ associação entre Baudelaire e Valéry serve também para legitimar essa leitura. A associação entre os dois poetas é central no projeto de Pacheco, tanto é que dois de seus cinco livros dedicados a Baudelaire aproximam os dois poetas já em seus títulos: Paul Valéry e o monumento a Baudelaire em Paris e $O$ mar através de Baudelaire e Valéry. ${ }^{12}$

A poética de Valéry, no Brasil, é associada também à estética concretista, movimento que, conforme Cacaso, no referido artigo, "opera uma divisão burocrática sobre o trabalho de criação poética, e a noção de experimento sofre uma restritiva especialização técnica". ${ }^{13}$ Uma vez mais, ainda que em outra perspectiva, são a técnica e o rigor, a forma e a matemática que informam o projeto dos poetas concretos, embora a referência não seja mais Baudelaire e, sim, para ficar no domínio francês, Mallarmé e Valéry. Pacheco destaca, assim, num só tempo, duas figuras que se tornarão importantes para dois movimentos literários de grande relevância nas décadas seguintes.

Guilherme de Almeida também contribui para a introdução dos dois autores no Brasil. É dele a primeira tradução de "Les Pas" de Valéry, publicada em seu Poetas de França em $1936 .{ }^{14}$ Nesse mesmo volume, ele apresenta também pela primeira vez sua tradução de sete poemas de Baudelaire, que depois farão parte de seu volume As flores das flores

10. CaCASo. "Atualidade de Mário de Andrade". In: Não quero prosa. Campinas: Unicamp, 1997, p. 162. 11. PACHeco, Félix. Do sentido do azar e do conceito da fatalidade em Baudelaire, op. cit., p. 36.

12. Cf. PACHeco, Félix. Paul Valéry e o monumento a Baudelaire em Paris. Rio de Janeiro: Oficinas Tipográficas do Jornal do Comércio, 1933; e PACHeco, Félix. O mar através de Baudelaire e Valéry. Rio de Janeiro: Oficinas Tipográficas do Jornal do Comércio, 1933C.

13. CACAso. "Atualidade de Mário de Andrade", op. cit., p. 164.

14. Almeida, Guilherme de. Poetas de França. São Paulo: Babel, 2011 [1936]. 
do mal, publicado em 1944. Como aponta Candido, as traduções de Guilherme de Almeida são um trabalho "mais sólido" que o de Pacheco, mas, acredito, guardam com ele certa afinidade. Assim como Pacheco, Guilherme de Almeida se interessa sobretudo por poemas da primeira parte das Flores do mal. Das 21 traduções que publica em suas Flores das flores, ele inclui apenas: "A une Passante", dos Tableaux Parisiens; "L'âme du vin", da séries dos vinhos; e "Les Litanies de Satan", de Révolte. Cabe, contudo, assinalar sua inclusão de "Une Charogne". Em sua nota à tradução do poema, comenta:

Une charogne... Popularmente, a pièce de resistance de Les Fleurs du mal. É a pintura, embora rude, emotiva, que um romântico-naturalista faz do mau cheiro. Tentei reproduzi-la em toda a sua natural, deliciosa "grosseria". Não se estranhe, pois, no meu texto, o termo "fedor" por exemplo: Baudelaire escreveu "puanteur", e não, burguesmente, "mauvaise odeur"...

O cuidado de Guilherme de Almeida não o impediu, contudo, no poema, de proceder a uma série de alterações significantes, como, por exemplo, a tradução de "Rappelez-vous l'objet que nous vîmes" por "Recorda o objeto vil que vimos". A introdução do adjetivo "vil", já no primeiro verso, qualifica o "objeto" que, em Baudelaire, se dá a ver sem qualidades. Mesmo se Guilherme de Almeida o faz, provavelmente, para conservar o alexandrino do poema francês, o resultado é o de qualificar o objeto observado.

Outro exemplo: no momento de descrever a carniça, Baudelaire, no início da terceira estrofe, declara: "Le soleil rayonnait sur cette pourriture". Ao refazer o verso, Guilherme de Almeida o traduz assim: "Reverberava o sol sobre aquela torpeza”. A transformação da "pourriture" em "torpeza", de certo modo, desnaturaliza o objeto, certamente para produzir uma rima com "Natureza" (Nature, em Baudelaire). O que salta aos olhos é uma valorização do metro e da rima, ou seja, da forma, ainda que isso implique uma alteração considerável na escolha imagética. O primado da forma é explicitado pelo próprio Guilherme de Almeida. Na mesma nota a "Une charogne", ele acrescenta: "Como em 'Hino à Beleza' (mas aqui com absoluto rigor), mantive as rimas graves e agudas alternando-se". ${ }^{16}$ É, uma vez mais, o "rigor de técnica" que prevalece, no caso, levado ao extremo, pois Guilherme de Almeida opta por retomar o critério da

15. ALMEIDA, Guilherme de. As flores das flores do mal. São Paulo: 34 Letras, 2010 [1944], p. 109. 16. Ibid. 
alternância das rimas, tão caro à poesia francesa devido à natureza aguda da própria língua, mas irrelevante na constituição de uma poética clássica em língua portuguesa.

Esse mesmo tipo de convenção de cunho academicizante será a opção dos tradutores de Baudelaire ao longo de toda a segunda metade do século xx. Nesse sentido, o seguinte comentário de Jamil Almansur Haddad, responsável pela primeira tradução integral das Flores do mal em língua portuguesa, publicada em 1957, é bastante esclarecedora. Afirma Haddad:

O vezo da tradução de Baudelaire pode ser entre nós levado à conta do triunfo da estética parnasiana. Só mesmo uma escola poética desta ordem, levando longe o sonho de apuro da linguagem e perfeição técnica, pode fazer da tradução de poemas um exercício realmente valioso. ${ }^{17}$

O que Haddad explicita vinte e cinco anos depois da "campanha" de Félix Pacheco é, uma vez mais, o primado da forma, aqui nomeado de "apuro da linguagem e perfeição técnica". Chama a atenção também a afirmação do "triunfo da estética parnasiana", em que retumba um elogio à geração de 45 , que, como vimos, cultiva uma concepção exterior da forma. Com efeito, esses princípios vão acompanhar a recepção e a tradução de Baudelaire ao longo de todo o século xx. Um exemplo que explorei em artigo anterior, ${ }^{18}$ a respeito do poema "LInvitation au voyage", ilustra bem o processo de apropriação academicizante em relação a Baudelaire no Brasil. No referido artigo, analiso diferentes traduções do poema, dentre as quais se destacam a de Guilherme de Almeida, pela importância que tem na recepção de Baudelaire no Brasil, assim como as de Jamil Almansur Haddad (de 1957) e de Ivan Junqueira (de 1985), por serem as duas primeiras traduções integrais de As flores do mal publicadas no Brasil. Um exemplo ilustrativo das posturas tradutórias são as reescritas do seguinte estribilho:

Là, tout n'est quordre et beauté,

Luxe, calme et volupté.

17. Baudelaire, Charles. As flores do mal. Tradução de Jamil Almansur Haddad. São Paulo: Max Limonad, 1981 [1957], p. 14.

18. Cf. FALeiros, Álvaro. Sobre uma não tradução e algumas traduções de "L' Invitation au voyage" de Baudelaire. Alea, vol. 9, n. 2, pp. 250-262, 2007. 
Sobressai nele o fato de o primeiro verso iniciar-se com a "ordem", sendo esta seguida pela "beleza", que está, por sua vez, em posição de destaque na rima. Quanto ao segundo verso, após descrever esse lugar misterioso como um lugar cheio de luxo e de calma, ele coroa a descrição do espaço com a "volúpia", ou seja, as imagens postas em relevo são a "beleza" e a "volúpia", envoltas por uma espécie de calma ordenada. Pelo lugar de destaque que ocupam no verso, a "ordem" e a "beleza" funcionam como síntese dos elementos que criam a atmosfera do universo encantatório que habita o poema baudelairiano. tradução:

Ao traduzir o referido estribilho, Guilherme de Almeida ${ }^{19}$ opta pela seguinte

Lá, tudo é ordem e nitidez

Luxo, calma e languidez.
Là, tout n'est qu'ordre et beauté,

Luxe, calme et volupté

Assim, o "belo" torna-se "nítido" e a "voluptuosidade" perde um pouco de ímpeto em seu sinônimo "languidez", ainda que a imagem retome a sensualidade sugerida. Esse apagamento da "beleza", exigido pelas escolhas da rima, produz uma oposição entre o primeiro verso, em que se destaca apenas a ideia de ordem, e o segundo, marcado pelo luxo e a languidez. Ao substituir "beleza" por "nitidez", Guilherme de Almeida produz um estribilho mais frio e racional, ao qualificar o belo como o nítido.

Jamil Almansur Haddad ${ }^{20}$ vai na mesma direção de Guilherme de Almeida, optando por um Baudelaire menos voluptuoso:
Lá tudo é belo e se ordena
Là, tout n'est qu'ordre et beauté,
- Luxo volúpia serena
Luxe, calme et volupté

Com efeito, as escolhas de Haddad levam a um ordenamento do discurso. Sua mudança na hierarquia faz com que, no primeiro verso, seja o belo que se ordena, transformando a "ordem" no predicado verbal da beleza. Quanto ao segundo verso, nota-se que "luxo, calma e volúpia" tinham o mesmo estatuto enumerativo, mas, na tradução, "volúpia serena" passa a ser aposto de "luxo", assumindo, dessa maneira, um caráter explicativo.

19. ALMEIDA, Guilherme de. As flores das flores do mal, op. cit.

20. In: BAUdelaire, Charles. As flores do mal, op. cit. 
O resultado é que, na imagem criada por Haddad, o que se destaca é a "ordem"; já "volúpia" perde força, pois, além de se tornar "serena" (oxímoro inexistente em Baudelaire), ela é reduzida a um aposto.

Em Ivan Junqueira, ${ }^{21}$ tradutor também fiel ao "apuro da linguagem e à perfeição técnica" e importante representante da geração de 45 , predomina uma vez mais a ordem, como se pode notar:

$\begin{array}{ll}\text { Lá, tudo é paz e rigor, } & \text { Là, tout n'est quoordre et beauté, } \\ \text { Luxo, beleza e langor. } & \text { Luxe, calme et volupté }\end{array}$

Em Ivan Junqueira, o que era "ordem" desloca-se à esfera do "rigor", modulação que torna essa passagem do poema uma espécie de panfleto parnasiano por sua aproximação entre rigidez e paz. Mas a paz, em Baudelaire, soa mais sensual e seu resultado parece aproximar-se mais do que Jean-Pierre Richard chama de "un état de paix ondulatoire". ${ }^{22}$ Assim como em Guilherme de Almeida, Junqueira introduz uma oposição inexistente no original. De um lado "paz e rigor", do outro "luxo, beleza e langor". Ainda que os sinônimos sejam próximos, o fato de modificar a ordem e, sobretudo, tirar o destaque dado à rima "beautélvolupté" faz com que o poema adquira um tom mais severo, fazendo de Baudelaire um poeta menos provocante do que de fato é.

Voltando uma vez mais a Antonio Candido, o crítico brasileiro já identificava nos primeiros baudelairianos brasileiros preocupação semelhante. Comenta Antonio Candido:

Os baudelairianos do decênio de 1870 foram portanto uma espécie de pré-parnasianos, sobretudo na medida em que aprenderam com o seu inspirador o cuidado formal, o amor pelas imagens raras, a recuperação do soneto e de outras formas fixas. [...] N'As flores do mal encontraram um tratamento não convencional do sexo, um lutuoso spleen

21. In: BAudelaire, Charles. As flores do mal. Tradução de Ivan Junqueira. Rio de Janeiro: Nova Fronteira, 1985.

22. RICHARD, Jean-Pierre. Poésie et profondeur. Paris: Seuil, 1995, p. 11. 
e um senso refinado da análise moral; mas refutaram ou não sentiram bem a coragem do prosaísmo e dos torneios coloquiais. ${ }^{23}$

Desse modo, se há uma mudança importante no modo de recepção de Baudelaire, uma vez que desde Félix Pacheco não se trata mais de emular o poeta francês e sim de traduzi-lo, a leitura de Baudelaire segue estetizante, levando com frequência a uma desnaturalização das imagens. Nas traduções, nota-se ainda, pela busca de um alexandrino rigoroso e de rimas perfeitas, o mesmo distanciamento que há nos pré-parnasianos de 1870 em relação ao prosaísmo e à coloquialidade existente n'As flores do mal.

A partir do que foi acima exposto, cabe sobretudo ressaltar que o tratamento academicizante dado a Baudelaire por Félix Pacheco anuncia uma nova atitude poética, que se tornará dominante nas décadas seguintes, e que é marcada pelo formalismo. É certamente o tratamento do poema a partir do primado do significante que aproxima a geração de 1945 e os poetas concretos. Nessa perspectiva, o desenvolvimento de técnicas composicionais é não só desejável, mas necessária para o domínio do verso. A reação academicizante e formalista que predomina nos anos 1950 e em parte dos anos 1960, ao que Cacaso chamou de "poética de inovação participante do modernismo", encontrou em Baudelaire, e na tradução de modo mais amplo, campos férteis para seu desenvolvimento.

Baudelaire, como se procurou mostrar aqui, por seu apuro formal e sua suposta postura "moral" serviu de duplo modelo, "educando" os sentidos e o espírito da geração que estava à época reagindo ao modernismo. A situação modelar de Baudelaire serviu, assim, de baliza para o desenvolvimento de uma poética do traduzir de cunho formalista que, por um lado, atendeu às necessidades de rigor técnico dos acadêmicos da geração de 45 e, por outro, graças ao desenvolvimento da linguística e da semiótica, ganhou contornos mais "científicos" no discurso e na prática dos concretos, sobretudo em Haroldo de Campos.

A obra de Félix Pacheco situa-se, pois, num ponto de inflexão; momento em que certo projeto modernista-nacional dá, na poesia, sinais de esgotamento. Voltar-se para autores como Baudelaire (admirado pela geração de 45) e Valéry (admirado pelos poetas concretos) prepara o campo para a elaboração de outra poética, mais formalista e, na falta de termo mais adequado, "internacional”. Uma das características da mesma será o

23. MEllo E souzA, Antonio Candido de. “Os primeiro baudelairianos", op. cit., pp. 45-46. 
estatuto que a tradução ocupa. Ela servirá tanto como lugar de exercício e de demonstração de apuro técnico para os poetas-tradutores quanto para a elaboração de outros cânones, como é o caso da retomada do paideuma poundiano pelos poetas concretos.

Enfim, Antonio Candido tem em parte razão quando afirma que, na primeira metade do século $\mathrm{xx}$, a presença de Baudelaire não é mais "decisiva para definir os rumos da produção poética, traçando a fisionomia de uma fase e, deste modo, assumindo uma importância histórica”. Digo em parte, pois, se é certo que os poetas relevantes do século xx não são baudelairianos, também parece possível considerar que o modo como Baudelaire é traduzido por autores como Félix Pacheco, Guilherme de Almeida, Jamil Almansur Haddad e Ivan Junqueira assume, sim, grande importância histórica, pois ajuda a traçar a fisionomia de uma fase em que a tradução não será mais emulação, mas lugar para se pensar e modo de se fazer poesia; o que define, em certa medida, os rumos da produção poética do período. Aí, dependendo de nosso grau de afinidade com poéticas mais românticas, modernistas, clássicas ou formalistas, poderemos dizer: bendito ou maldito Baudelaire, esse que vingou nestes trópicos.

Álvaro Faleiros é professor livre-docente de literatura francesa na Universidade de São Paulo. Seu principal tema de pesquisa é a tradução poética, sobretudo de autores franceses como Apollinaire, Mallarmé e Baudelaire. 